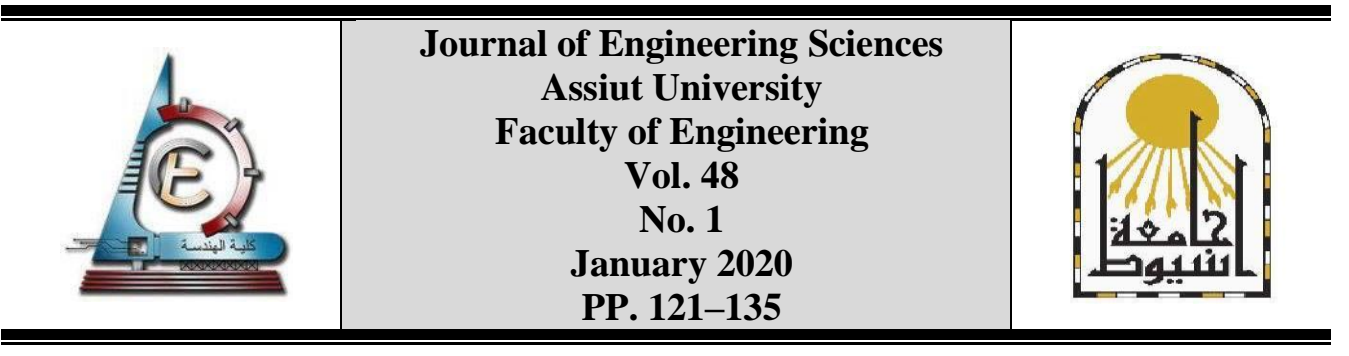

\title{
FABRICS AS AN INVENTIVE BUILDING MATERIAL AND THEIR COMPATIBILITY WITH FLEXIBLE ARCHITECTURE I. ABDELSABOUR
}

Department of Architecture, Faculty of Engineering, Mattaria Branch, Helwan University. E-mail: inas.abdelsabour@m-eng.helwan.edu.eg

Received 2 July 2019; Accepted 30 July 2019

\begin{abstract}
There was a continuation in utilizing and applying of fabrics (such as foils, fiberglass and some innovative fabrics) which became an inspiring tool in architecture both in construction and architecture, to suit various ideas and requests with notable impacts on building performance in comparison with other materials. The aim of this study is to identify the essential features of fabric materials and how the fabrics may promote the flexible architecture approach. It explores the role of the fabric in the innovative constructions by facilitating the techniques and principles of flexible architecture in design and construction to examine how the compatibility of cloth to be achieved. To attain the aim, the paper was based on SWOT analysis method as a way to examine the flexible approach of fabrics on the architectural performance.
\end{abstract}

Keywords: Fabric, Flexible Architecture, Innovative Materials, Adaptable Architecture, SWOT Analysis

\section{Introduction}

Fabric structures help in creating limitless design opportunities with potentials in architecture. Twenty years ago, "Fabric Architecture" referred to outdoor tents or canopies, while today, an expanding range of materials was significantly improved the structure, lighting, and graphics technology features, which allowed fabrics to take on new roles; as multimedia canvas, iconic sculpture, and branded symbol skins [1]. Thus, the fabric could offer flexible designs to architecture by providing creative solutions to adapt with specific spaces in different environments. Nowadays, many architects were exploring a countless usage of fabric in architectural applications; that changed the space's nature and act as a landmark in its region, that may need optical lightness, transparency, or exciting envelopes, Fig. 1 [1]. The study concentrated on fabrics that were used for achieving the flexible purposes for improving the building ability. Flexible buildings can adjust to the changing needs and patterns, via environmental, economic and aesthetical ones, either prior or after occupation. Accordingly, innovative fabrics were varied to conserve limitless possibilities in fabric architecture, to reach the flexible architecture which depended on Adaptability, Movability, Interactivity, and Transformability.

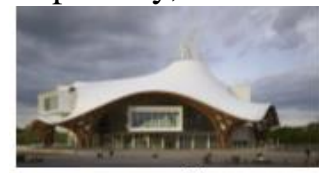

Centre Pompidou, Metz

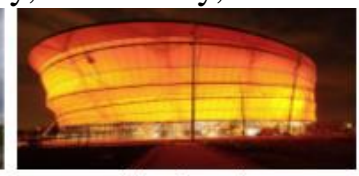

Zenith of Strasbourg

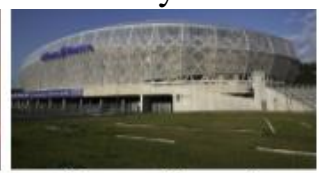

Allianz Stadium, Nice 


\subsection{Research aims}

The research approach was to measure the compatibility of using fabric as a building material, and how it may well attain the concept of flexible architecture, either in design or construction stages, by investigating and emphasizing on the fabric's importance to improve the building's abilities and properties.

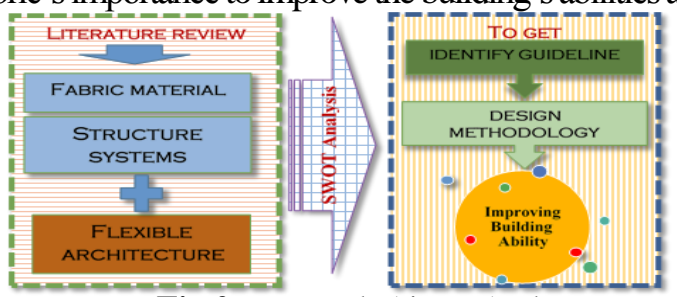

Fig 2. Research Aims [Author]

\section{Literature review}

\subsection{Fabric in architecture (textile, fabric, and fiber)}

The textile was defined by "The Textile Institute" as "a general term applied to any manufacture from fibers, filaments or yarns characterized by flexibility, fineness and high ratio of length to the thickness" [2]. Recently textile products may be made from a mixture of fibers, films, yarns, sheets, foams, furs, or leather. While "Fabric" includes a broader selection of materials than "textile".

Further, it could refer to fabric construction or to fabric structure, and may be described as a thin, flexible material made of any mix of cloth, fiber, or polymer (film, sheet, or foams). Whereas "Fiber" was initially a thread-like, which could be natural or artificial; the natural ones had limited properties which reduced their application. However, artificial fibers could be obtained by using a wide range of materials [2,3]. Such as; ETFE (Ethylene Tetra Flouro Ethylene), AFRP (Aramid Fibers Reinforced Polymer), PVC (Polymerizing vinyl chloride), PET (Polyester / Polyethylene Terephthalate Fibers), ePTFE (expanded Polytetrafluoroethylene Fibers), PES (coated Polyvinyl) and Metal fibers [4].

\subsection{Types of fibers and its application}

There were several common types of fibers that used in buildings, which differs according to its properties, cost and application in buildings, as seen in Table.1.

Table 1.

Common types of fibers, modified from $[1,5,6]$

\begin{tabular}{|cl|}
\hline Material & \multicolumn{1}{c|}{ Features } \\
\hline Polyester & $\begin{array}{l}\text { The most used fiber, due to its reduced price, flexibility, good mechanical } \\
\text { performance and the expected lifespan. Strength and durability, make it very common } \\
\text { for temporary and seasonal structures. The laminated or coated with PVC films were } \\
\text { usually the least expensive option for longer-term fabrications. }\end{array}$ \\
\hline Polyethylene & $\begin{array}{l}\text { It was used for low-budget applications despite its shorter life span compared to } \\
\text { polyester. Knitted fabrics for shading requests were the most promising uses of high- } \\
\text { density polyethylene in architecture. }\end{array}$ \\
\hline Fiberglass & $\begin{array}{l}\text { It was mostly used for permanent heavy-duty applications due to its high modulus of } \\
\text { elasticity, the tensile strength, its essential high resistance to fire and UV degradation. }\end{array}$ \\
\hline Nylon & $\begin{array}{l}\text { Was always used for lightweight, stretchable projects and products which require } \\
\text { relatively low mechanical properties. Thus, it was commonly used in small temporary } \\
\text { and deployable structures. }\end{array}$ \\
\hline Expanded & $\begin{array}{l}\text { Was relatively new and used for seasonal and deployable structures due to its high } \\
\text { translucency, strength, flexibility, long lifespan and high chemical resistance. }\end{array}$ \\
\hline PTFE & $\begin{array}{l}\text { was widely used in architecture, due to the reduced mechanical performance, suitable } \\
\text { for small deployable tents and umbrellas due to their flexibility, good resistance to } \\
\text { chemicals, and corrosion from sunlight exposure. }\end{array}$ \\
\hline
\end{tabular}




\subsection{Fabric patterns}

The fabric/membrane was made of yarns that were fabricated the fibers, which were organized in parallel or woven together, by techniques act a significant role on its ability to bend and extend, [7, 8]. Knitted textiles; had better elasticity and form finding, which could be helpful when applied to a highly geometrical surface. Woven textiles; the most used types of architectural applications, which composed of two types of yarn; the wrap and the weft. And Non-woven textiles; that built by the overlapping of randomly oriented yarn welded together by an adhesive, with high tensile strength and lower stretch level.

From the architectural point of view, woven fabrics usually useful in outdoor application due to its high strength. Besides, fabric weaving pattern state water tightness, translucency, sound-reducing, and it could be used as load-carrying structural elements.

\subsection{Properties of fabric materials}

There were several properties must be considered during the selection of the fabric' type for structure; mechanical and non-mechanical properties.

\section{Table 2.}

Properties of Fabric Material, Modified From [1, 2, 5, 9]

- Tensile strength; to measure the required force to split the material.
Tear strength; which was the resistance to propagate an existing tear.
elastic properties; such as stiffness, which was the link between the modulus of
Adhesion strength; to measure the bond's strength between the base material
and coating or film laminate that protect it for evaluating the strength of welded
joints.

\subsection{Types of fabrics/textiles}

In fabric architecture there were three main forms of fabrics that were used; Coated textiles, Open mesh fabrics, and Foils [8].

\subsubsection{Open mesh textiles}

They were used as a permeable textile for the solar control, with a definite level of permeability to light, wind and moisture. As well, they were coated either before the weaving process or by dip coating then laminated. So, knitted high-density polyethylene or metal shade fabrics were trendy, due to its amazing elasticity, cheap cost, and adequate life span [8]. In consequence, it might be used in renovating old buildings, as in the old textile factory that was transformed with wave shape of the custom metal mesh into remarkable theatrical, concert performances and fashion shows building, Fig. 3 [10]. And in the Rice 
University's parking garage, the wrapped façade with printed shade screens coated PES tensile mesh cladding with fig leaf pattern, Fig. 4 [11].

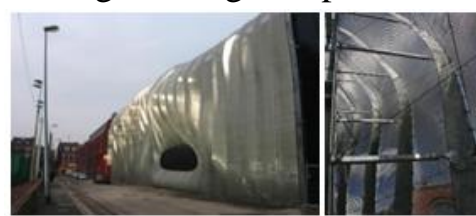

Fig. 3. The Old Textile Factory [10]

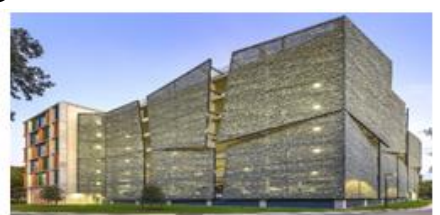

Fig. 4. Rice University Office Building [11]

\subsubsection{Coated and laminated textile fabric composites}

Fabrics for architectural purposes were mostly a combination of textile fabrics (two or more layers) and polymer coatings (at least one polymeric layer), which were bonded by an added adhesive [2]. The coating had a major role in bend cracking resistance, mechanical strength, and protection from the weather's effects, light transmittance, and fire protection. Besides, it helped in creating a smooth surface, reducing the possible pollution area, and improving the fabric's aesthetic values and functionality $[2,6]$. Coated textiles could be divided into three main types, each one has a different internal structure that provides to use in a different application, as shown in Fig. 5.

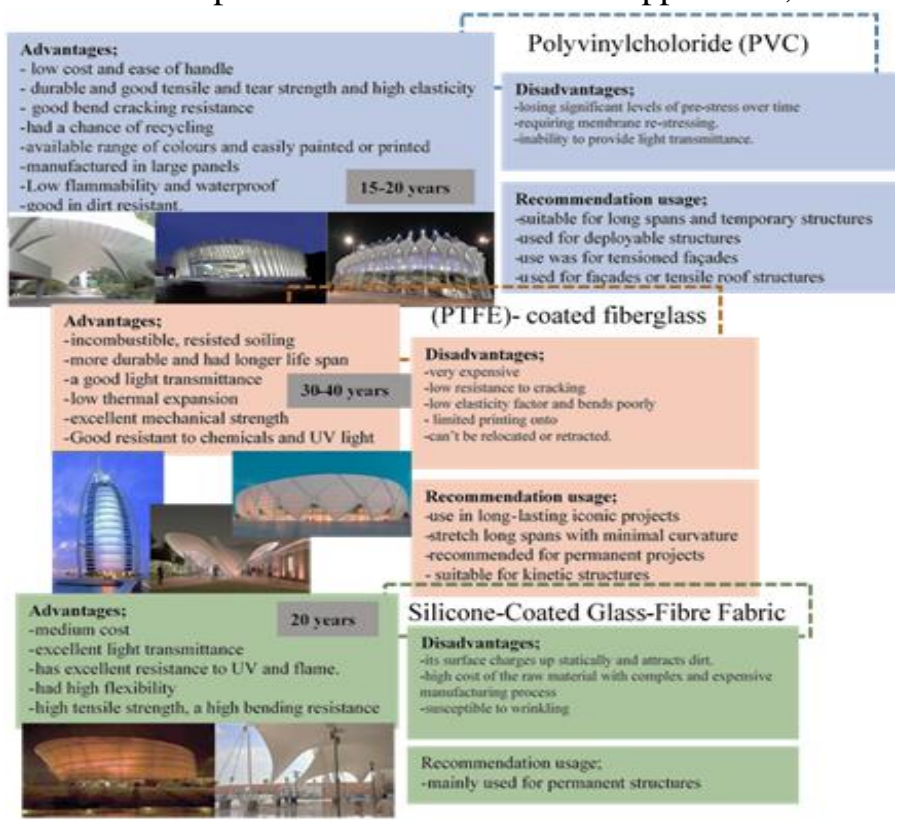

Fig. 5. Types of Coated Fabrics in Buildings, Modified From [2, 5, 6, 9]

\subsubsection{Foils}

Foils had great advantages; it is a very low self-weighted with freedom in shape and was placed where the translucency was needed. It could be applied to roofs or façades element (as air cushion) or as a small-span tensile structure (as a single layer), Fig.6 [1]. 


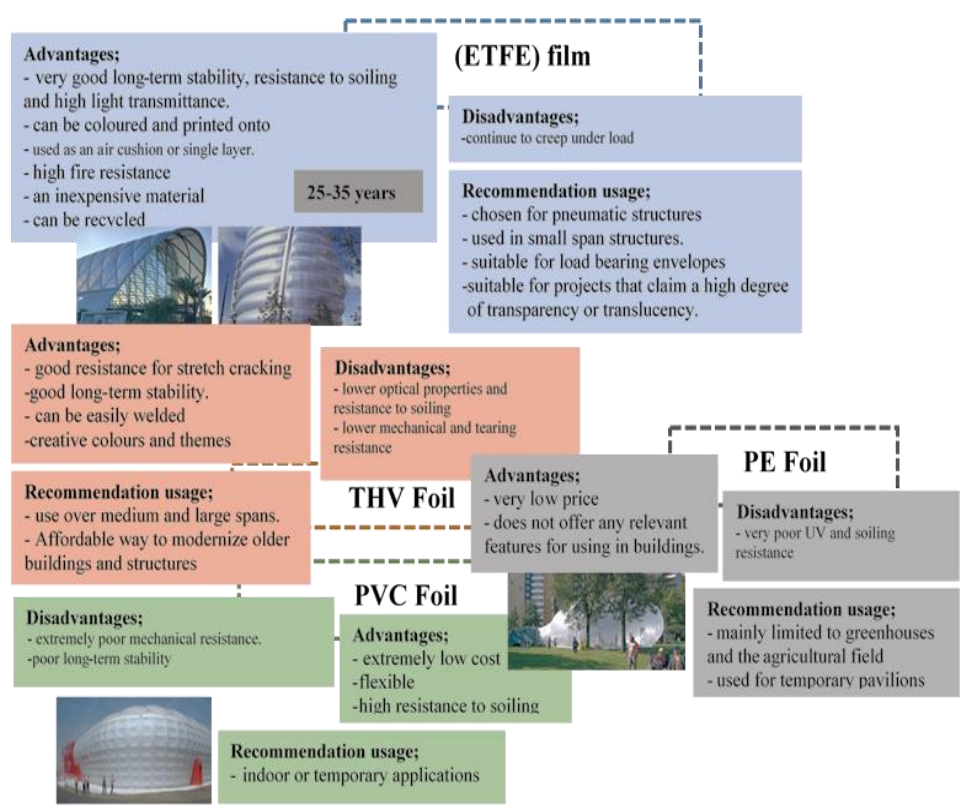

Fig. 6. Types of Foils in Construction, Modified From [2, 5, 1, 6, 12, 13]

\subsection{Innovative fabric material}

New ideas were studied to improve fabric materials, to suit architectural functions, environmental condition's control, and energy production, as well as keeping it lightweight.

\subsubsection{Green roof textile}

These units were thin, flexible, ideal for application on lightweight curved roofs, and to protect the textile from ultraviolet light, for an environmental structure. It was based on the hydroponics system for living roofs, walls and vertical gardens, help in merging with the surroundings [1]. Such as Green textile with a soil substrate, Fig. 7.a, and green hydroponic textile with an inert substrate in Fig. 7.b. Or by Photosynthesis Membrane, that used closed-loop vertical photobioreactor plants as algae, which were placed in transparent plastic bags on top of the textile membrane, Fig. 7.c. [1].

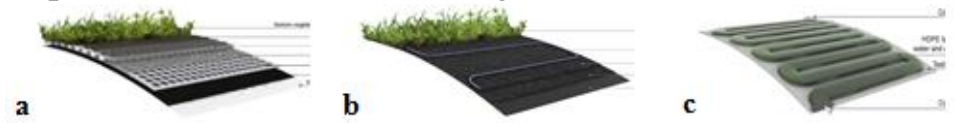

Fig. 7. a) Green textile with soil substrate, b) Green hydroponic textile with inert substrate, c) photosynthesis membrane [1]

\subsubsection{Intelligent/ smart textiles}

Intelligent textiles could sense and respond to environmental conditions or stimuli via digital elements in their structure. So, the material's properties were able to modify their position, stiffness, conductivity in response to environmental changes such as humidity or temperature. They may be; passive (sense to environment), active (react to the sensed stimuli) and very smart textiles (ability to sense, react and adapt their act), as in Table. 3, [2, 8, 14]. 
Table . 3.

Some Types of Intelligent Textiles, Modified From [2, 8, 14]

\begin{tabular}{|c|l|}
\hline Type Of Textile & \multicolumn{1}{c|}{ Main Features } \\
\hline Conductive Materials & Which were able to carry and conduct electric energy? \\
\hline $\begin{array}{c}\text { Electricity Generating } \\
\text { Fabric }\end{array}$ & $\begin{array}{l}\text { With built-in solar cells via printing, and aids in generating energy } \\
\text { that could be used as building envelopes. }\end{array}$ \\
\hline $\begin{array}{c}\text { Shape Memory } \\
\text { Materials (SMMs); }\end{array}$ & $\begin{array}{l}\text { That responded to extemal stimuli (electric and magnetic fields, pH- } \\
\text { value, temperature, stress or UV-light) by transforming their shape. }\end{array}$ \\
\hline $\begin{array}{c}\text { Phase Change } \\
\text { Materials (PCMs) }\end{array}$ & $\begin{array}{l}\text { It included microcapsules that store and release energy via the } \\
\text { materials' phase change that may be used in curtains, roof } \\
\text { coverings, and canopies to collect solar thermal. }\end{array}$ \\
\hline Textile Interfaces (TIF) & $\begin{array}{l}\text { a woven textile with conducting light units, that can make the fabrics } \\
\text { conduct electricity and shine, as glass fiber-monofilaments. }\end{array}$ \\
\hline
\end{tabular}

\subsubsection{Photovoltaic cells in foil and membrane}

A layer of photovoltaic solar cells (PV) could be compressed and sealed in a transparent membrane. The shape, size and the pattern of the solar cells were arranged in a way which allowed continued flexibility of the material. These cells present a lot of future potential; it does not require an added sub-structure, but act as an integrated part of the building envelope. From an architectural viewpoint, it not only provides electricity, but also offer needed shading to reduce the solar heat gains, and thus helped to reduce cooling loads in summer, Fig. 8 [15, 16].
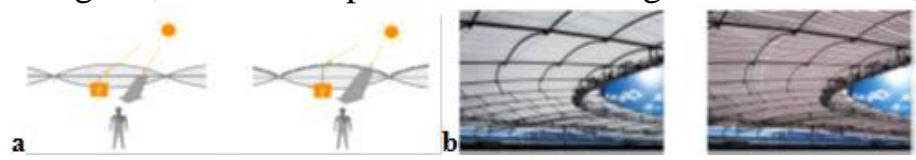

Fig. 8. a. PV in (middle or top) pneumatic structure. b. A Photomontage of PV $[15,16]$.

\subsection{Types of fabric structure}

Fabric structures were a kind of buildings in which the load-bearing capacity was attained via tension stress in the greater part of the elements, such as cables, foils or technical fabrics. Thus, it was divided into three main categorizes; Boundary tensioned membranes, Pneumatic or air-supported structures, and Cable-nets or cable-beams, each type will be illustrated via its main features, concept, and the suitable fabric that could be used, as seen in Fig. 9.

\subsection{Design process}

Architects had to prepare the geometry creation to determine the required fabric, the size of the structural system and the required foundations, through;

- Understanding the applied loads by the fabric itself (as pre-stressed, pre-tension units)

- Calculating the loads that the structure will be exposed to (wind or snow) [9].

Thus, the design process had three main stages: the form-finding, the static analysis, and the patterning, with the probable addition of dynamic analysis if required;

- Form finding; in this step, material properties were ignored, and the shape is directed by both the geometry of the supporting structure and the proposed prestress on the membrane, when the ideal shape was found, the forces and shortest distance paths were continually updated. Many techniques were improved to detect the structure's form; such as soap film models; for using rigid and/or flexible boundaries. Scale models; were commonly used but have drawbacks of not being 
able to show the non-uniform stresses on the surface. And computer simulation; by using force-density and dynamic relaxation methods to offer more accuracy and gave better control on the pre-stress, [5, 8, 18].

- Analysis/Structure Modelling; after creating the model, it was analyzed to define the loads that will create stresses and deformations on the textile, along with the transferred loads to the supporting structure. So, the stresses in individual elements were calculated according to the deformation caused by their connecting nodes deflections $[8,18,19]$. Subsequent to this analysis, the textile then had to be patterned and manufactured.

- Patterning; to fabricate the fabric, it must be divided into 2D triangular pieces by unfolding the 3D model. Thus, the joints' tracing lines must be included in the formfinding and load behavior analysis to get the optimal result. Therefore, when "unfolding" the fabric for fabrication patterning, the actual fabric will be slightly reduced. For that reason, the patterning process occurred by three steps; Seam (joint) line; that effect on the panel's size, and the aesthetics that concern with the structure's appearance. Flattening; was the conversion of the seam lines into 2D plane flat surface by triangulation method. And Tension compensation by size reduction; that required to reduce the strip's size prior to assembly to obtain the needed pre-tension $[5,8,18]$.

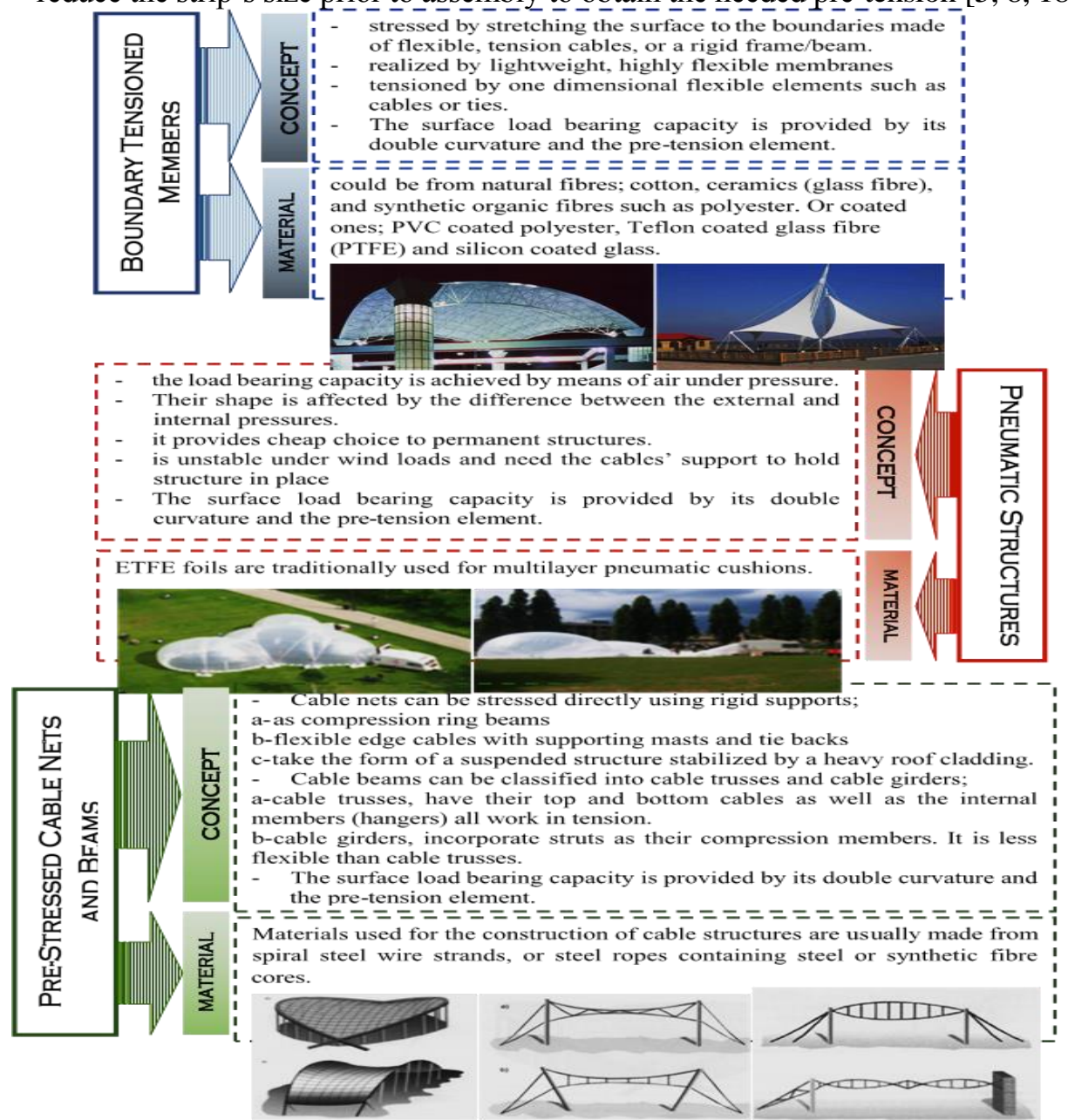

Fig. 9. Types of Fabric Structures, Modified From [1, 5, 6, 9, 17] 


\subsection{Flexibility and flexible architecture}

Flexibility means; the quality of bending easily without breaking, or the ability of modification, alteration to various purposes or conditions; freedom from stiffness or rigidity [20]. From an architecture perspective; flexible architecture was defined by Kronenburg as a "fluid architecture that became complete once people inhabit it and used $i t$ ". Thus, the designing for flexibility raised as a result of the changing in the occupant's needs, and emerged gradually in response to the evolving social and economic requires due to the environments' transformation part by part. So, flexibility could be stated as the ability to adapt to varied requirements of the built environment by incorporating new technologies to change the building's function [21]. So that, it contained the changes and challenges of the dynamic world, with a design that was shaped by way of adding the present's requests including the possible future's changes.

Architects consider fabric as a trendy building material due to powerful range reasons it provides; $[9,22,23]$

- Design Flexibility; due to its strength and elasticity that hold varying loads for further design capabilities, to provide clear, free-span areas with maximum floor space.

- Permanent/Transportable; it could be used for permanent purposes or temporary usage, and its structure was easy for moving to a new location or resell.

- Cost Effectiveness; it was cheap and less installation preparation, when compared to brick or concrete, and it could be applied in unsettled weather and then removed.

- Transparency and Climate Control; it allowed the daylight penetration or as an insulator to reduce the usage light and energy's amount in the operating costs.

- Atmosphere Impression; fabric could give another impact than solid materials, due to its softness and the way of flowing and folding, and a sense of security and privacy.

In design, there were many principles of flexibility that met the designer's predictions for possible future changes to fit better by enabling adjustments as needed to support function through effective solutions to the today and tomorrow's problems. Thus, flexibility allows buildings to remain in use longer, for preventing costly and wasteful full demolition and rebuilding [24, 25].

\section{Research method/ analytical study}

\subsection{Analytical study aims}

The analytical study was applied to state the main consequence of using fabrics as a building material in flexible architecture to improve the building ability.

\subsection{Research statement}

That there were many opportunities of using fabrics in architecture to attain the flexible architecture's concept by defining the possible applications for buildings, specifically for flexible building.

\subsection{Analytical methodology}

The SWOT analysis method was performed assisting in decisions making to develop the design plans through; the internal factors; Strengths to indicate the main themes of the design concept. Weaknesses, to illustrate the shortcomings of using the process. The 
external factors; Opportunities, point to the factors that could be applied to enhance its application. Threats, which imply the negative effects on its application.

SWOT analysis method helped in achieving the analytical study to assess the most used techniques between architectural and structural solutions in flexible architectural design goal. Thus case studies were analyzed according to those features to measure how fabrics could reach the proposed hypothesis.

\section{Results (applying of fabric in flexible architecture by SWOT analysis)}

Four different aspects could be utilized in buildings to be flexible building; it must be capable of adaptation, transformation, mobility; and interaction [21].

\subsection{Adaptation}

It means the adjustment to different functions, could be changeable with a multi-purpose space or climate, and freedom usage of users' activities to create the client's desired space, with adaptive systems that offer more occupant comfort, use less energy, and contain better space efficiency than static building $[21,26]$. As in the "Smart" façade' concept by Bára Finnsdottir, the Fraunhofer Institute in Dresden that kept space' temperature without using any electricity. It's composed of an individual circular flower-like units, each one had a disc of fabric with shape-memory wires running through it, which contract to open and to close the textile pieces according to the external temperature, Fig. 10 [27]. And at the King Fahd National Library in Riyadh by Gerber Architects, 2013, that got heat support with a tensile PTFE-coated twisted textile squares façade to shade the building and filled the interior spaces with natural light without blocking occupant views, Fig. 11 [28]. Also The mixedused building by B + U Architects, Los Anglos 2009, that responded to the urban setting, by a high tech enclosure system from multiple layers of fabrics with various levels of transparencies, to adjust for diverse exterior light states and offer stable levels in the office spaces, Fig. 12 [29]. Then, the Kolon Tower by Morphosis Architects in South Korea, 2018, a crafted high-performance aramid fabric was used in varying degrees of opacity and thickness in vertical layers to scatter the strong sunlight, which could be switched off to achieve a smooth organic form with minimal connections, Fig. 13 [30]. Then, these examples were analyzed by SWOT analysis process, Fig.14.

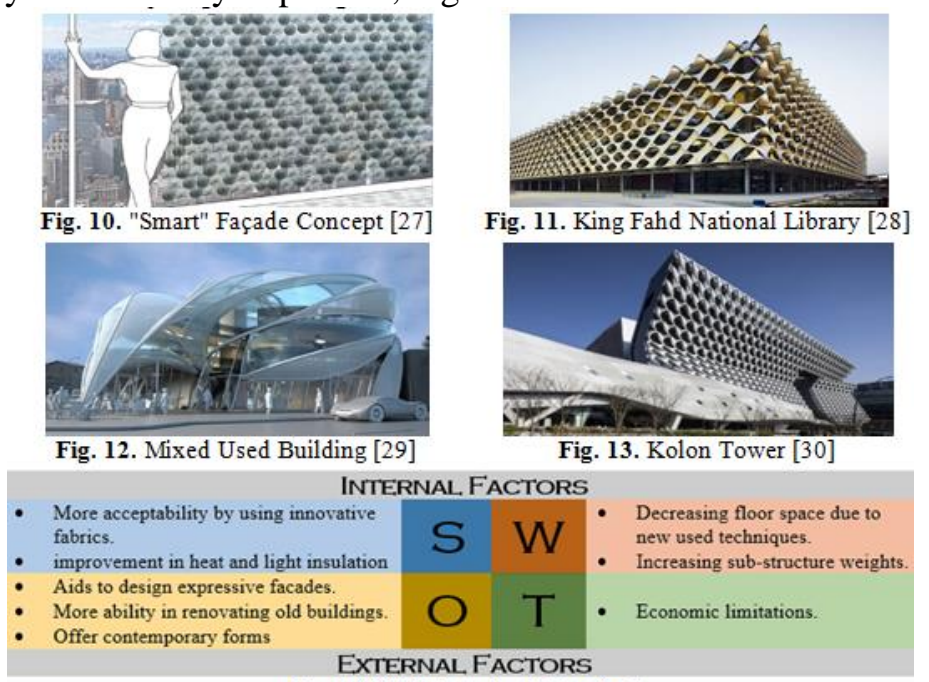

Fig. 14. SWOT Analysis [Author] 


\subsection{Mobility}

It refers to temporary buildings that offer physical movement from place to another by relocatable or repositionable structures. The gains lied in the flexibility and diversity of their purposes and its reusability that allowed for unimaginable motivating projects and ideas [21, 26]. Such as, The Cloud by Jasmax in New Zealand, 2011, which was a semi-permanent, multi-purpose event and exhibition structure from a series of varied height structural trusses to achieve the cloud's organic shape. The roof was made from coated PES fabric and ETFE wall panels, which creates a window-like appearance, Fig.15 [31]. And the Portable Serpentine Pavilion 2015 by SelgasCano Architects, that was based on visitor's experience with structure, light, transparency, lightness, form, color and materials to combine with landscape. This was achieved by forming a double-layered shell, made of opaque and translucent ETFE in varying colors, Fig.16 [32]. The London Shooting Venue by Magma Architecture at the London 2012 Games, which was skinned in a white, double curved PVC membrane façade and brightly colored dots openings. The used materials were reused, every joint was designed for reassembly, and the cladding minimized the need for artificial lighting, Fig. 17 [33]. Then, these examples were analyzed by SWOT analysis process, Fig.18.

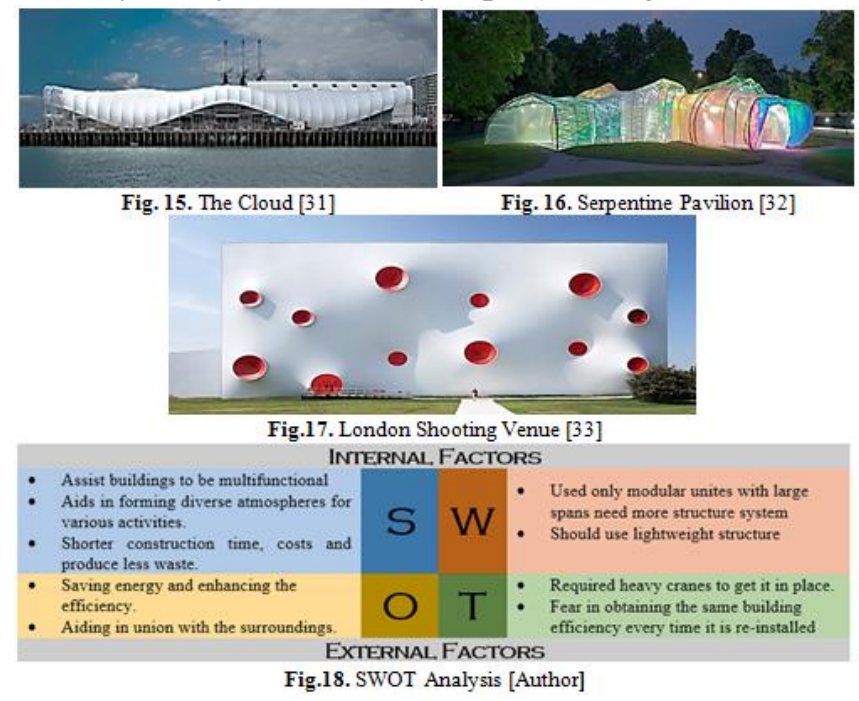

\subsection{Transformation}

These buildings were characterized by modular design roofs, windows or other façade's parts (capable of adding, removing, opened or closed units) and able to modify their form by the physical alteration to their structure or skin components. So that it could give the impression of being alive to react with the external environment and respond to climatic conditions [21]. For instance, The Fortress Arena in Austria by Kugel and Rein Architects, 2006, a multimedia event center, the roof was created from ePTFE fabric to build a retractable circular shelter, protect the area from bad weather conditions and expand the outdoor space, Fig.19 [34]. And in Tenerife Astronomic Observatory by Pedretti of Airlight, the structure's opening and closing units were attained by the power of pressurization. Two steel arches lifted and rotated on a central axis pulling the PVC fabric which inflated and pulled up the smaller arches to the pneumatic shell shape, Fig.20 [35]. In addition, The Dynamic Mashrabiya of Al Bahr Towers in Abu Dhabi by Aedas Architects 2012, a thin screen of PTFE fabric mesh panels with an origami pattern was 
driven by a linear actuator. Each unit was an umbrella-like, which opened and closed during the day in response to the sun's movements, Fig. 21 [36]. Besides in the Swiss University, by Dominique Perrault Architecture 2014, a 3D zig-zag façade from movable aluminum fabric mesh panels, was used to renovate its exterior and benefited from solar protection gave it a unique appearance. The panels were motorized and moved on rails for efficient solar protection, and natural ventilation, Fig.22 [37]. Then, these examples were analyzed by SWOT analysis process, Fig. 23.
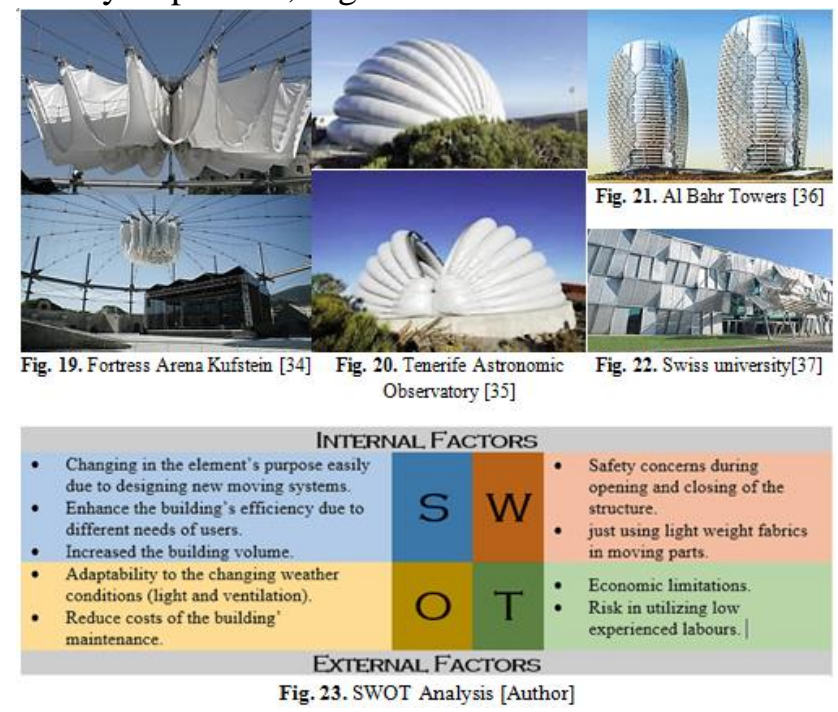

\subsection{Interaction}

These buildings prepared an interaction between building, people and appliances that responded to external stimuli, such as environment, usage, or occupation. The interaction relies on the technological system's usage in the formation of the interactive building, which response to users' requirements in automatic or natural ways [21, 38]. Such as the dynamic skin of Media-TIC, by Enric Ruiz-Geli of Cloud 9 in 2011, that had two systems from ETFE cushions consist of three layers with two air chambers. For flexibility, the south façades could be inflated or deflated as needed, which were activated by sensors. While the southwest façade used vertical cushioned panels, which had a nitrogen and oil mixture that temporarily merged into a "cloud" and transformed into translucent, Fig.24 [39]. Also, the Swiss Pavilion at Shanghai Expo 2010, by Buchner Brundler Architects, that was covered with a curtain that had a semi-transparent solar technology of woven aluminum elements to produce energy that was released individual LED flashes that varied according to the intensity and angle of light. These electronic sensors that reacted to light, turn solar radiation into a visible form of energy, Fig. 25 [40, 41]. Besides the facade of Atelier a Torcé factory by Batir France in 2007 that was transformed into a display of light color, and detailed graphics by using large panels of illumination and media mesh. Through daylight, the stainless steel facade sparkles at the sunlight, while at night flushes with the reflected light of its inserted weatherproof LEDs, Fig.26 [42]. Also by installing an energy-efficient membrane that used printed organic photovoltaic (OPV) at "solar trees" in the German Pavilion by Schmidhuber at Expo 2015, an energy-efficient membrane shelter of high aesthetic and technical quality to generate energy, Fig. 27 [43]. Then, these examples were analyzed by SWOT analysis process, Fig.28. 


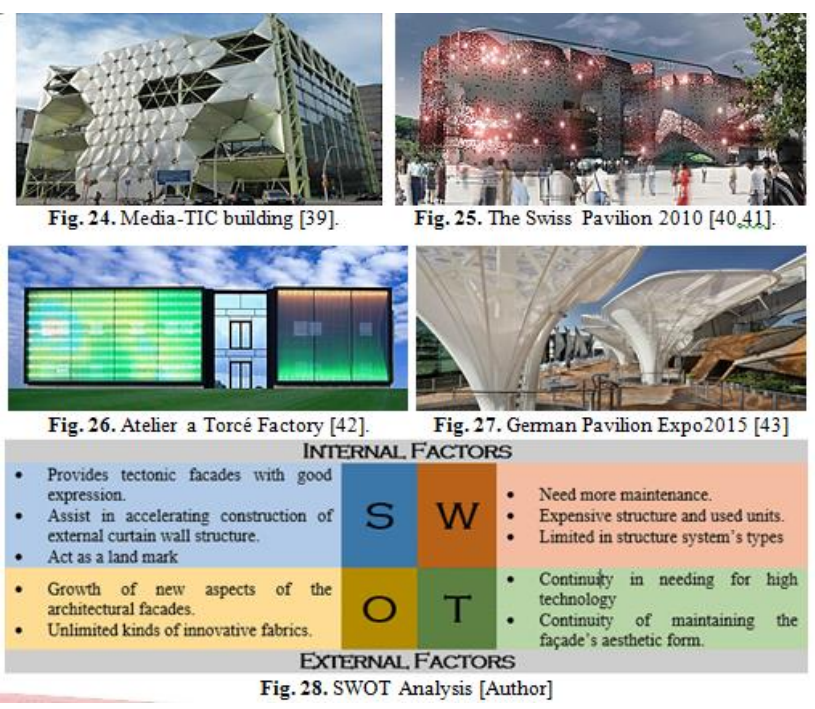

\section{Discussion and conclusion}

The study introduced the relation between the fabric types as a building material and the flexible architecture through its concept of applying in different buildings. By analyzing the case studies via SWOT analysis process, the internal factors (strength, weakness) must be improved and external factors (opportunities, threats) should be upgraded to maximize strengths and minimize weaknesses. The research concludes some points lead to a proposed methodology (concerned with material, techniques and function), Fig. 29, which could help the designer how to use fabric to attain the flexible characteristics of buildings.

- A well consideration of fabric structures design and construction may allow for the wide and popular application of fabric of permanent structures.

- Over cladding concept by covering old buildings with a modular fabric cladding panel which acts as a new 'skin' for new uses: a low carbon solution that will give a building more life as well as reducing electricity bills.

- The fabric could achieve its high functionality and aesthetic qualities by means of optimum manufacturing and light-technical specifications.

- An increasing trend towards static or dynamic envelopes of Public buildings, office buildings, shopping centers......etc.

- More freedom in design an applying of fabric range, which included standard products as well as customized ones for visual richness.

- Architectural design freedom and economics with rapid solutions and modernization.

- High-tech fabrics can develop a new invention of screens and shades are energy efficient, sustainable, attractive and functional. 


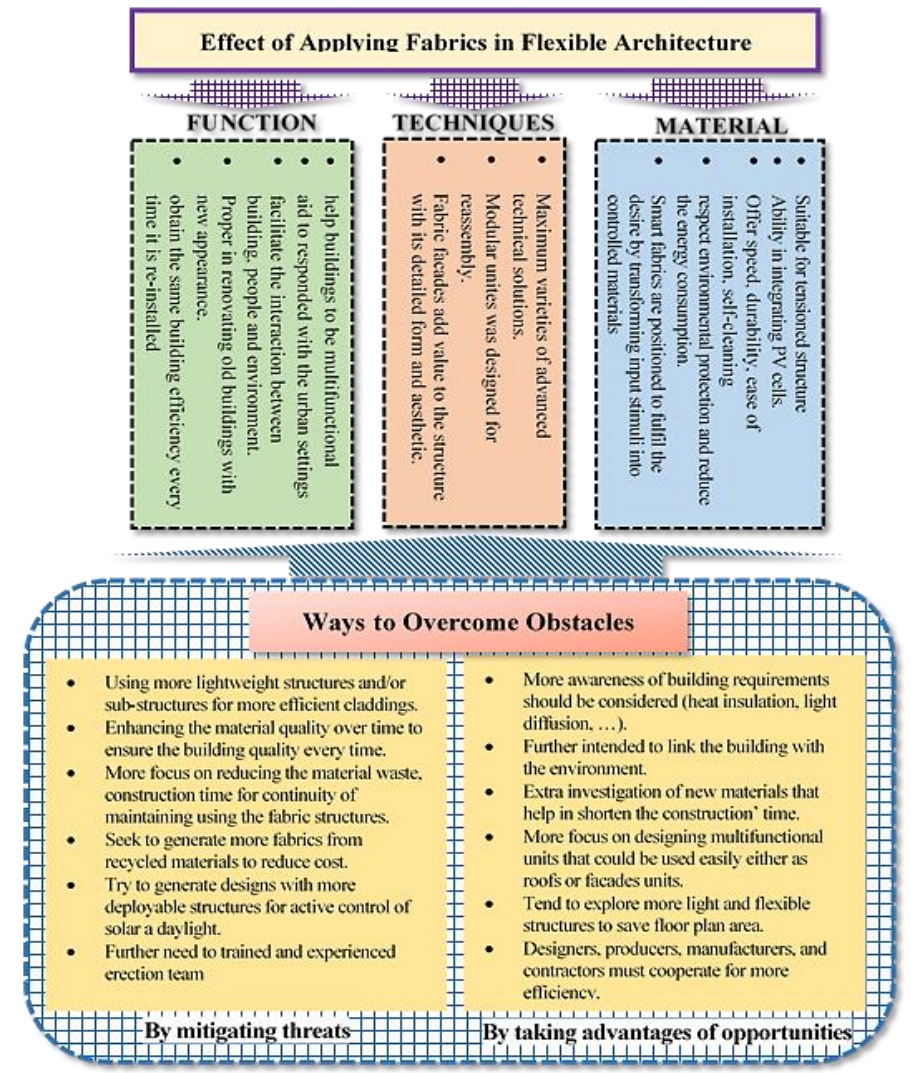

Fig. 29. The Proposed Guideline for Architect [Author]

\subsection{Suggested Methodology for applying fabrics in flexible architecture}

Based on the previous analysis and the concluded guideline for architects who could use fabrics a building material in a flexible way, a proposed methodology was deduced as follow, Fig. 30. The methodology was gathered from the relation between the used material and the structure system to attain the flexibility techniques that leads to achieve the human needs.

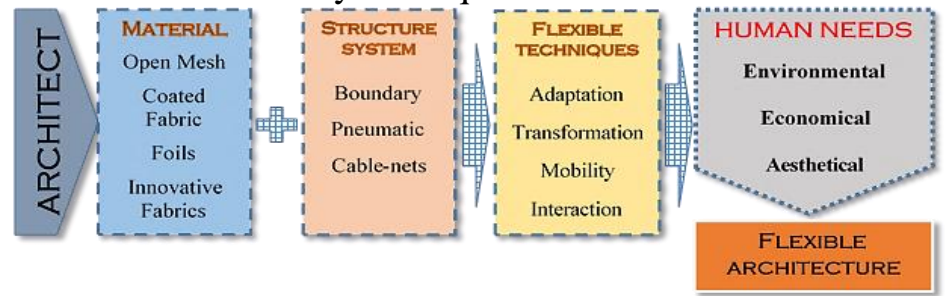

Fig. 30. The Proposed Methodology [Author]

From Human needs point of view, it could be appeared that all flexible techniques could attain the Aesthetical needs for occupants. While the Economical needs could be attained by Adaptation, Mobility and Interaction. Then, the Environmental needs could be achieved by Adaptation, Transformation and Interaction techniques. On the other hand, from the flexibility application perspective, it is cleared that both of Adaptation and Interaction can implement all human needs, followed by Transformation and Mobility.

Accordingly, from the obtained guide line for design with fabrics, the architect should start with the material selection according to the design's required structure system. At that 
point, it will facilitate in gaining the requisite flexible architecture technique that will consequently satisfy the human needs, Fig. 31.

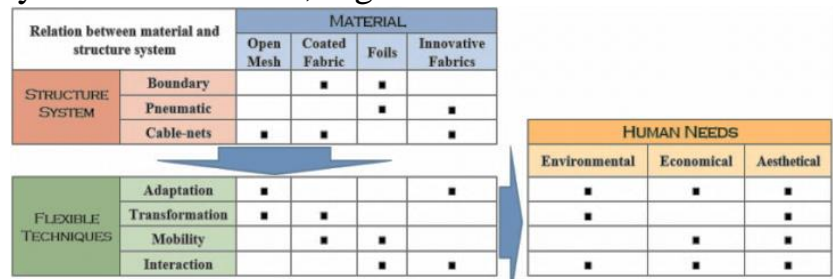

Fig. 31. Application of the Proposed Methodology [Author]

\section{REFERENCES}

[1] Llorens, J., "Fabric Structures in Architecture", Woodhead Publishing, Elsevier, pp.25:78, 159:182, 2015.

[2] Kuusisto, T., "Textile in Architecture", Tampere University of Technology, Master Thesis, pp. 8:76, 2010.

[3] Corazza, C. "Mechanical Characterization of Technical Textiles for The Screen-Printing: Experimental Tests and Numerical Analysis", PhD thesis, Politecnico di Milano, Milan, 2006.

[4] Knippers, J., Cremers, J., Gabler, M. and Lienhard, J., "Construction Manual for Polymers + Membranes", Birkhauser Gmbh, pp.50: 53, 2011.

[5] Son, M., "The Design and Analysis of Tension Fabric Structures", Master of Engineering in Civil and Environmental Engineering, Massachusetts Institute of Technology, pp.16:17, 2007.

[6] Beccarelli, P., "The Design, Analysis and Construction of Tensile Fabric Structures, Biaxial Testing for Fabrics and Foils", PoliMI SpringerBriefs, pp. 9:33, 2015.

[7] DOI 10.1007/978-3-319-02228-4_2

[8] Shaeffer, R.E., “Tensioned Fabric Structures: A Practical Introduction”, American Society of Civil Engineers Press, New York, pp.25:65, 1996.

[9] Pohl, G., Milwich, M., Baier, B., and Pohl, J., "Textiles, Polymers and Composites for Buildings", Philadelphia; Woodhead Publishing, pp 49:190, 2010.

[10] Sonjoy D., and B.Tech, "Analysis, Design and Construction of Fabric Structures", The Master builder, pp. 106:112, August $2013 . \quad$ available on: https://www.masterbuilder.co.in/ebook/2013/August2013_eBook/August2013.pdf (12/11/2018)

[11] http://www.gkdmetalfabrics.com/blog/old_textile_factory_is_transformed_with_wave_of_ custom_gkd_metal_mesh.html (1/12/2018)

[12] https://fabricarchitecturemag.com/2018/02/01/architectural-shading-systems-find-newmarkets/ (10/1/2019)

[13] http://www.tensinet.com/index.php/projects-database/projects?view=projectandid=4330 $(31 / 12 / 2018)$

[14] https://inspiration.detail.de/mobile-action-space-103435.html?lang=en (31/12/2018)

[15] Moor, T., Marin, A., and Häberle, J., "An Aesthetic Approach to The Use of Textiles in Architecture" pp.483:499, available on http://www.drs2014.org/media/654285/0280file1.pdf $(21 / 8 / 2018)$

[16] Ghorbanalavi, F., and Bahemat, S., "Performance Characteristics and Practical Applications of Common Building Polymeric Materials for Building Envelope", Journal of Energy and Economic Development, pp.13:33, August 2018

[17] Stegimaier, T. "High Performance and High Functional Fibers and Textiles", Woodhead Publishing Series in Textiles, pp. 89:119, 2005,

[18] DOI.org/10.1533/9781845690885.2.89

[19] Lewis, W. 'Tension Structures Form and Behavior", Reston, VA: Thomas Telford Books, pp.3:12, 2003.

[20] Bridgens, B., Gosling, P. and Birchall, M.J.s., "Tensile fabric structures: Concepts, practice \& developments”. Structural Engineer, No. 82. pp.21:27. 2004. 
I. Abdelsabour, Fabrics as an inventive building material and their compatibility with flexible architecture

[21] "Tensile Structure Design an Engineer's Perspective", Architectural Design magazine, Vol .76, No. 6, pp.92: 95, 2006.

[22] (Oxford Dictionary Online)

[23] https://en.oxforddictionaries.com/definition/flexibility (13/1/2019)

[24]Kronenburg, R., "Flexible: Architecture That Responds to Change", Laurence King Publishing, pp. 89: 231, 2007.

[25] http://www.fabricstructure.co.nz/why-fabric/why-use-architectural-textiles/ (12/11/2018)

[26] Alaraji, K., and Jusan, M., "Flexible Architectural Design and User Participation", available on https:/www.researchgate.net/publication/262002345_flexible_architectural_design_and_user_participation(12/10/2018)

[27] Kronenburg, R., "Flexible Architecture: Continuous and Developing", "Building Dynamics: Exploring Architecture of Change", Routledge, Taylor and Francis Group, pp. 47: 66, 2015

[28] Bharatkumer, A., "Flexible Architecture, what value does flexible architecture add to dwellings?", Master Theses, pp.11:16, 2015

[29] Kronenburg, R.'s lecture on flexible architecture at the Building Centre in London, 5 March 2011 , source: http://vimeo.com/21803296

[30] https://www.fraunhofer.de/en/press/research-news/2015/april/saving-energy-with-smartfacades.html (17/9/2018)

[31] https://www.architectmagazine.com/technology/detail/gerber-architekten-unveils-bothform-and-function_o (18/11/2018)

[32] https://www.designboom.com/architecture/b-u-architects-mixed-used-building-la/ (24/11/2018)

[33] https://www.architectmagazine.com/project-gallery/kolon-one-only-tower_o (24/11/2018)

[34] https://www.structurflex.com/projects/the-cloud/ (5/12/2018)

[35] https://www.dezeen.com/2015/06/22/serpentine-pavilion-2015-iwan-baan-londonselgascano/ (22/12/2018)

[36]https:/www.world-architects.com/ca/magma-architecture-berlin/project/london-shooting-venue (14/1/2019)

[37] https://www.architectmagazine.com/project-gallery/fortress-arena-kufstein (3/1/2019)

[38] _ "Designing, Detailing and Building with Textiles", Projects realized with different fabric, Special guest lecture at textile roofs, pp.8-12, 2008. available at: https://www.tensinet.com/files/TensiNet_Publications/TensiNews15-1.pdf (1/1/2019)

[39] http://www.mgsarchitecture.in/projects/511-al-bahr-towers-abu-dhabi-investment-councilnew-headquarters.html (31/12/2018)

[40]https://www.commercialarchitecturemagazine.com/3-d-facade-uses-movable-mesh-panels-2/ (19/12/2018)

[41] Acharya, L., "Flexible Architecture for The Dynamic Societies Reflection on a Journey from The 20th Century into The Future", Master Thesis, pp.15:30, 2013.

[42] Kolarevic, B. and Parlac, V., "Adaptive, Responsive Building Skins, Building Dynamics: Exploring Architecture of Change", Routledge, Taylor and Francis Group, pp.109:135, 2015.

[43] https://iart.ch/en/-/die-fassade-des-schweizer-pavillons-auf-der-expo-2010 (19/12/2018)

[44] https://www.designboom.com/architecture/swiss-pavilion-at-shanghai-world-expo-2010/ (19/12/2018)

[45] http://www.gkdmetalfabrics.com/projects/atelier_a_torc.html (25/12/2018)

[46] https://www.archdaily.com/639156/germany-pavilion-nil-milan-expo-2015-schmidhuber (9/4/2019)

\section{الأنسجة كمواد بناء مبتكرة ومدى ملاعمتها للعمارة المرنة}

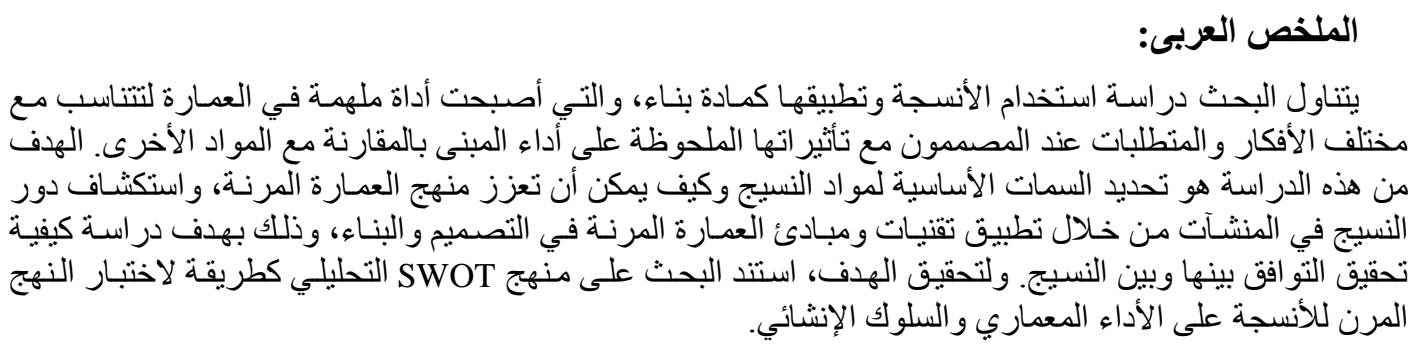

